\title{
Nilai Edukasi Metafora Teks-teks Seksual dalam Serat Centhini Karya Pakubuwana V
}

\author{
Nurnaningsih \\ Universitas Veteran Bangun Nusantara Sukoharjo
}

\begin{abstract}
Abstrak
Tema mengenai ajaran seks yang termuat dalam SC karya Pakubuwana V banyak dituangkan dalam bentuk bahasa-bahasa metafora. Masyarakat Jawa masih menganggap tabu masalah seks. Pembicaraan tentang seks dianggap tidak senonoh. Akan tetapi di dalam $S C$ penulis mampu menampilkan model penyampaian pendidikan seks secara baik dan santun. Penulis $S C$ berkomunikasi tidak hanya menggunakan ungkapan harfiah (literal meaning) saja, melainkan terkadang juga menggunakan ungkapan yang bermakna figuratif (metaphorical meaning). Pemahaman hakikat seks yang benar akan menjadikan seseorang mengerti pada sangkan 'asal usul' dan paran 'tujuan akhir hidup' yang akan dilalui oleh setiap manusia. Pemahaman sangkan paraning dumadi ini akan lebih mudah diajarkan jika mempergunakan gaya bahasa metafora.
\end{abstract}

Kata kunci: Pakubuwana V, Serat Centhini, metafora, seks.

Abstract

The theme of the teaching of sex contained in the $S C^{1}$ s work poured Pakubuwana $\mathrm{V}$ many languages in the form of a metaphor. Java community is still taboo subject of sex. Talks about sex are considered indecent. But in $S C$ authors were able to show a model of delivering good sex education and manners. Author $S C$ communicates not only use literal expression (literal meaning) only, but sometimes also used the phrase meaningful figurative (metaphorical meaning). Understanding the nature of sex are really going to make someone understand the sangkan 'origin' and famine 'the ultimate goal of life' which will be passed by every human being. Sangkan paraning dumadi understanding of being taught this will be easier if you use the metaphor language style.

Keywords: Pakubuwana V, Serat Centhini, metaphor, sex.

\section{PENDAHULUAN}

Pakubuwana V lahir pada hari Selasa Kliwon, 5 Rabingulakir Dal 1711 (13 Desember 1784) wuku Tambir, windu Adi pada pukul 13.00. Beliau lahir di Karaton Surakarta. Nama kecil Pakubuwana V adalah Raden Mas Gusti Sugandi. Pakubuwana V adalah putra laki-laki pertama Pakubuwana IV. Beliau lahir dari garwa padmi 'permaisuri'. Pada usia 36 tahun beliau naik tahta menggantikan ayahnya dan sering mendapat sebutan Pakubuwana V (Kajawen, 1939: 485).

Pakubuwana V adalah seorang raja Surakarta yang terkenal sebagai pemrakarsa pembuatan buku tentang ensiklopedia Jawa. Serat Centhini (yang selanjutnya dalam penulisannya disingkat SC) atau Suluk Tambangraras merupakan salah satu kekayaan di antara ribuan naskah Jawa yang terbagi dalam 12 jilid dan memiliki keistimewaan kandungan isi teksnya. Naskah ini ditulis pada tahun 1814-1823 M. Tim penulis dipimpin langsung oleh Kangjeng Adipati Anom Amangkunegara III yang setelah menjadi raja kemudian bergelar Sinuhun Pakubuwana V dan bertahta selama tiga tahun (1820-1823 M) (Kajawen, 1939: 487). Tema mengenai ajaran seks atau perilaku seks orang pada jaman dahulu juga dimuat dalam $S C$. Karena kandungan isi $S C$ yang begitu luas dan menyeluruh, maka serat ini sering disebut sebagai "Ensiklopedi Kebudayaan Jawa" atau merupakan babon 'sumber' ilmu pengetahuan yang memuat semua kawruh 'ilmu pengetahuan' Jawa (Marsono, 2008: 1). 
Sang Koordinator Putera Mahkota menghendaki agar penyampaian dongeng-dongeng, peristiwa-peristiwa, dan wejangan-wejangan harus diselingi dengan cerita/lakon asmara yang hangat dan mantap agar cerita menarik dan berkesan bagi pembaca. Konon penyampaian yang bernafaskan porno digubah oleh ketua tim sendiri. Setiap uraian gambaran keadaan dituangkan secara mendetail dengan gaya bahasa yang memukau dalam bentuk tembang Macapat (Marsono, 2006: 4).

\section{... / dènvarsa mungkasi pupuh / \\ 1) kono kêrêp dèn-gadaa // (Serat Centhini III, Pupuh 191 Asmaradana, bait 13)}

olehnya ingin mengakhiri perang

di situ seringlah dipukul-pukul

Dalam data larik ke $7 \mathrm{di}$ atas terdapat metafora alat seksual laki-laki yaitu gada 'alat pemukul/gada'. Alat kemaluan laki-laki diungkapkan dengan metafora gada 'alat pemukul' karena kemiripan bentuk fisik alat kemaluan laki-laki dengan senjata gada. Data larik ke 6-7 di atas juga terdapat metafora aktivitas seksual yaitu dènyarsa mungkasi pupuh, kono kêrêp dèngada-a 'keinginannya ingin mengakhiri perang, disitu seringlah digada'. Ketika ingin segera mengakhiri peperangan, sang senapati harus sering memukulkan gadanya di tempat yang diinginkan. Ketika terjadi persenggamaan, keluar masuk alat kemaluan laki-laki diusahakan supaya teratur dan sering agar sang wanita merasa geli.

Pendidikan seks bagi sebagian besar orang Jawa masih dianggap tabu. Pembicaraan tentang seks dianggap tidak senonoh. Akan tetapi di dalam SC penulis mampu menampilkan model penyampaian pendidikan seks secara menarik tetapi tetap santun dengan metaforametafora.

Metafora digunakan untuk mendeskripsikan sesuatu dengan sesuatu yang lain seperti diungkapkan oleh Black (2008: 102), "metaphor was defined as saying one thing and meaning another". Pendapat lain dikemukakan oleh Wahab (1990: 65) yang mengatakan bahwa metafora adalah ungkapan kebahasaan yang tidak dapat diartikan secara langsung dari lambang yang dipakai, melainkan prediksi yang dapat dipakai oleh lambang maupun oleh makna yang dimaksudkan oleh ungkapan kebahasaan tersebut.

Metafora seringkali digunakan untuk menjelaskan sesuatu yang abstrak agar lebih bersifat konkrit sehingga di dalam metafora terdapat dua buah domain yaitu domain yang abstrak dan domain yang konkrit di mana domain tersebut berkorespondensi satu sama lain. Korespondensi tersebut disusun agar tercipta sebuah pemahaman domain atau ranah yang abstrak menjadi lebih konkrit (Kovesces, 2003: 8). Oleh karena itu penulis tertarik untuk meneliti nilai-nilai edukasi teks-teks seksual dalam Serat Centhini karya Pakubuwana V.

\section{Metode Penelitian}

Peneliti dalam penelitian ini menggunakan bentuk penelitian kualitatif deskriptif. Naskah yang dipilih untuk dikaji menjadi sumber data dalam penelitian ini adalah naskah SC 12 jilid yang isi teksnya baku tersimpan di Perpustakaan Jarahnitra Yogyakarta. Hasil pelatinan 12 jilid ini kemudian diterbitkan oleh Karkono Partokusumo atau Kamajaya melalui Yayasan Centhini Yogyakarta pada tahun 1986. Penelitian ini juga perlu didukung dengan sumber data sekunder/penunjang yang lain, yaitu berupa buku-buku, karangan pendek, penelitian, tulisantulisan ilmiah, artikel, naskah Jawa yang sejenis antara lain Serat Gatholoco, Serat Kadis Saresmi, Serat Asmaragama, Marta Pangrawit, naskah seminar (dipilih) yang secara khusus membicarakan metafora atau sekurang-kurangnya ada kaitannya baik langsung maupun tidak 
langsung terhadap SC, Pakubuwana V, ajaran seksual Jawa, serta didukung oleh para informan yang mengetahui karakteristik $S C$.

Data primer/utama dalam penelitian ini adalah data kebahasaan yang berwujud larik yang mengandung nilai-nilai pendidikan seksual dalam $S C$. Data sekunder/penunjang adalah informasi dari para informan yang mengetahui seluk beluk/karakteristik $S C$, maupun informasi mengenai $S C$, ajaran seksualitas, biografi Pakubuwana $\mathrm{V}$ yang termuat dalam buku-buku, artikel, penelitian-penelitian, naskah Jawa yang sejenis, maupun tulisan ilmiah lainnya. Pengumpulan data yang dipergunakan dalam penelitian ini ada dua jenis yaitu bersifat noninteraktif dan interaktif. Metode noninteraktif dilakukan dengan content analysis, sedangkan metode interaktif dilakukan dengan teknik wawancara mendalam (in-depth interviewing). Proses analisis data dalam penelitian ini bersifat interaktif, yaitu analisis data dengan menggunakan langkah-langkah: reduksi data, sajian data, dan penarikan kesimpulan.

\section{HASIL PENELITIAN DAN PEMBAHASAN}

Masyarakat Jawa masih menganggap tabu masalah seks. Pembicaraan tentang seks dianggap tidak senonoh. Akan tetapi di dalam $S C$ penulis mampu menampilkan model penyampaian pendidikan seks secara baik dan santun. Manusia berkomunikasi tidak hanya menggunakan ungkapan harfiah (literal meaning) saja, melainkan terkadang juga menggunakan ungkapan yang bermakna figuratif (metaphorical meaning). Adegan seksual dalam SC memang diungkapkan secara terbuka dan menimbulkan kesan erotis yang kuat dan vulgar, tetapi dalam bahasa aslinya (bahasa Jawa) sebenarnya diungkapkan dengan gaya bahasa yang sangat indah. Teks setelah diterjemahkan ke dalam bahasa Indonesia, mungkin terkesan tampak sangat tidak senonoh dan cabul. Kesan itu memang tidak dapat dihindari dalam menerjemahkan gaya bahasa.

Serat Centhini yang memuat teks-teks metafora seksual terdapat di dalam larik-larik tembang. Satu pada 'bait' kadangkala ditemukan satu metafora alat seksual, kadangkala ditemukan juga metafora aktivitas seksual maupun metafora dampak aktivitas seksual.

2) aja nganti tinêmpuh / ... jangan sampai dilakukan

sinanggaman luwange nguni /

disenggamai lubang kemaluan terlebih dahulu

(Serat Centhini III, Pupuh 189

Dhandanggula, bait 26)

SC III Pupuh 189 Dhandhanggula bait 26 larik ke 5 di atas terdapat metafora alat seksual wanita yaitu luwang 'lubang'. Metafora ini dibangun atau diciptakan berdasarkan persamaan atau kemiripan wujud fisik alat kemaluan wanita yang berlubang.

3) gêmboke kang ginogohan// (Serat Centhini Jilid VIII Pupuh

486 Maskumambang bait 17)

Data larik ke 4 di atas terdapat metafora alat seksual wanita: gêmboke 'lubang kunci'. Kata gembok 'lubang kunci' merupakan metafora dan diciptakan berdasarkan kemiripan wujud fisik alat kemaluan wanita yang memiliki lubang.

(4) mustikaning rahsa mulya / rinêksa pra jawatadi / aran Sang Hyang Otapatra / Sang Hyang Gambira sêsilih //
Mustika rasa mulia

dijaga para dewa luhur

disebut Sang Hyang Otapatra

Sang Hyang Gambira namanya 
(Serat Centhini III, Pupuh 190

Kinanthi, bait 24)

SC III Pupuh 190 Kinanthi bait 24 larik ke 3 di atas terdapat metafora alat seksual wanita yaitu mustika 'permata/emas'. Alat kemaluan wanita diungkapkan dengan metafora yaitu mustika 'permata/emas' atau sebuah benda yang sangat berharga dan harus dijaga. SC III Pupuh 190 Kinanthi bait 24 larik ke 5 di atas terdapat metafora alat seksual wanita yaitu Sang Hyang Otapatra 'Sang Hyang Otapatra'. Tirta yiyit 'air lekat dan licin' dalam kemaluan wanita diungkapkan dengan metafora yaitu dengan sebutan Sang Hyang Otapatra. SC III Pupuh 190 Kinanthi bait 24 larik ke 6 di atas juga terdapat metafora alat seksual yaitu Sang Hyang Gambira'Sang Hyang Gambira'. Tirta yiyit dalam kemaluan wanita diungkapkan dengan metafora yaitu Sang Hyang Gambira. Secara persepsi, datangnya tirta yiyit akan membuat hubungan suami isteri lebih menyenangkan/menggembirakan.

(5)

\section{Mêlar-mingkus daya wiwaraning /}

baga kang wus (m)bathok/ ... / angsal ing prang tandhing / kudu nganggo lagu // (Serat Centhini III, Pupuh 193 Mijil bait 13)
Buka tutup daya pintu

kemaluan yang sudah seperti batok

$\cdots$

dan ketika berperang

harus memakai irama

Data larik ke 1-2 di atas terdapat metafora alat seksual wanita yaitu wiwaraning baga 'pintu/gerbang kemaluan wanita'. Data larik ke 3 di atas juga terdapat metafora aktivitas seksual dengan tuturan prang tandhing, kudu nganggo lagu 'ketika berperang, harus memakai irama'. Proses persenggamaan diungkapkan secara metafora sebagai sebuah prang tandhing 'peperangan' di rananggana 'medan perang'.

6)

Pamudharing rahsa putih /

sarta soking rahsa mêrta /

asrêp kalangkung nikmate /

...

duk mangkono angganda rum /

(Serat Centhini III, Pupuh 191

Asmaradana, bait 31)
Lepasnya rasa putih serta tumpahnya rasa menenteramkan menyejukkan sangat nikmatnya

ketika itu tercium bau harum

Data larik ke 1 di atas terdapat metafora alat seksual laki-laki yaitu rahsa putih 'rasa putih'. Air mani laki-laki diungkapkan dengan tuturan metafora rahsa putih 'rasa putih' karena kemiripan secara fisik memiliki warna putih. Dalam data larik ke 1-3 di atas juga terdapat metafora dampak aktivitas seksual yaitu asrêp kalangkung nikmate 'menyejukkan nikmat sekali'. Dalam data larik ke 6-7 di atas masih terdapat metafora dampak aktivitas seksual lainnya yaitu angganda rum 'mengeluarkan bau harum'.

Dampak proses persenggamaan ini kedua pasangan akan merasakan nikmat. Suasana rasa nikmat disamakan dengan suasana yang asrêp 'menyejukkan, dingin'. Peristiwa pertemuan dua rasa yang berbeda atau saat-saat yang indah ini digambarkan dengan metafora angganda rum 'mengeluarkan bau harum' atau akan tercium aroma harum.

Panarik sêndhaling limpung / Menarik dan mengeluarkan senjata

7) maju myang mundurirèki / Maju dan mundurnya 


\section{(Serat Centhini III, Pupuh 190 Kinanthi,}

bait 37)

Data larik ke 1 di atas terdapat metafora alat seksual laki-laki yaitu limpung 'alat pemukul'. Dengan demikian di dalam satu pada 'bait' kadangkala hanya ditemukan satu metafora alat seksual, akan tetapi di dalam satu pada 'bait' selanjutnya terdapat metafora alat seksual, metafora aktivitas seksual maupun metafora dampak aktivitas seksual.

Pembaca secara sepintas bisa menikmati dan menghayati citraan tentang tingkah laku orang sedang bereaksi dalam hubungan seksual yang dilukiskan secara emosional. Kita bisa menghayati cerita seks dalam $S C$ dengan indah karena pengarang mampu menggunakan bahasa yang mengandung sarana estetis literer. Ini merupakan kekuatan daya magis sebuah bahasa. Kekuatan estetis yang menggambarkan hubungan seks dengan penuh nafsu, tetapi tampak santun. Semua diwujudkan dengan kata-kata yang mempesona, penuh getaran seks.

Pengeksplorasian masalah seks oleh manusia sesungguhnya bahwa seks memang menjadi salah satu kebutuhan pokok baginya. Seks tidak dapat dilepaskan atau dipisahkan dari hidup dan kehidupan manusia. Seks adalah pengiring serta pelengkap kehidupan manusia. Seks sangat penting dalam kehidupan manusia baik secara ragawi maupun kerohanian.

Masalah seksualitas merupakan masalah yang fundamental dalam kehidupan manusia. Hanya sayangnya masalah seksualitas masih dianggap tabu oleh kebanyakan orang. SC menyajikan secara menarik hal-hal mengenai sanggama yang dianggap porno. Setiap gambaran keadaan dituangkan secara mendetail dengan gaya bahasa yang memukau dalam bentuk tembang macapat. Pakubuwana V sangat mahir menyajikan tema seksualitas dengan metafora sehingga memberikan efek bagi pembaca bahwa paparan seksualitas itu menjadi indah, menarik, dan tidak vulgar serta layak dijadikan warisan budaya yang penting.

Bagaimana sepasang manusia mempersiapkan diri secara baik dalam olah cipta, rasa, dan karsanya pada waktu menjelang, pada saat dan sesudah melakukan hubungan penyatuan raga dan jiwa. Hal ini banyak dianggap oleh masyarakat Jawa sebagai mitos karena mereka kebanyakan tidak mau belajar spiritualisme Jawa. Konsep spiritual leluhur Jawa itu dapat dijumpai dalam $S C$. Pakubuwana V mengemas ajaran seksual Jawa yang penuh dengan gaya bahasa metafora selalu mengkaitkan dengan nama-nama dewa, istana para dewa yang indah, benda-benda perang, atau benda yang dianggap suci, sakral yang dimiliki oleh para raja atau dewa.

Ajaran seks dalam $S C$ tersebar mulai jilid I sampai dengan XII berisi tatacara kehidupan seks dan seni ranjang yang tersusun dalam kalimat-kalimat indah penuh nuansa sastra dan simbol-simbol dalam bentuk metafora. Berbagai istilah untuk menggambarkan alat seksual lakilaki maupun perempuan, akivitas seksual maupun dampak aktivitas seksual tersaji secara menarik. $S C$ merupakan tuntunan pada intisari kenikmatan bersenggama. Dalam $S C$ diajarkan teknik-teknik dan rahasia untuk mencapai puncak hubungan seksual dengan metafora.

Sikap atau perasaan Pakubuwana V dalam menyajikan teks seksual dalam $S C$ pada hakikatnya adalah dalam rangka menyadarkan manusia agar selalu ingat pada bibit kawite 'asal mula terjadinya'. Kawruh seks yang diajarkan dalam $S C$ sebenarnya mengingatkan bahwa manusia hendaknya selalu sadar akan bibit kawite 'asal mula terjadinya' dan harus berupaya memaknai makna hidup ini seperti dalam SC jilid 3 pupuh 191 Asmaradana bait 21 dan 22 sebagai berikut.

Pamarsudining sarêsmi

kang wus sun-gêlar sadaya

kanggo srana lantarane

dènnya yun angawruhana
'Ilmu tentang senggama

yang sudah saya ajarkan

sebagai sarana peyebabnya

olehnya ingin mengetahui 
mring asal wijinira

manungsa sajatinipun

kasbut têmbung paribasan

(SC III/191/Asm/21)

9)

Sing sapa wonge tan uning
marang wiji asalira
sayêktine nora wêruh
mring jati paraning sêdya
kang têmbe wêkasannya
kacrita kurang satuhu
mring sampurnaning kamuksan
(SC III/191/Asm/22)

tentang asal-usul benihmu

manusia sebenarnya

disebut dalam peribahasa'
'Barang siapa tidak mengenal terhadap benih asalmu sebenarnya tidak mengetahui tujuan sejati manusia hidup besok akhirnya dikatakan sungguh tidak mengetahui terhadap kesempurnaan kematian'

Penggunaan metafora dalam $S C$ sering digunakan untuk mengungkapkan pengalamanpengalaman yang unik dan terkadang terjadi di luar dimensi ruang dan waktu yang dapat dihayati oleh manusia, sehingga sukar atau bahkan tidak mungkin dilukiskan dengan tepat. Hal semacam ini, penggunaan metafora sangat membantu mengungkapkan pengalaman kepada orang lain. Penggambaran proses persetubuhan dalam $S C$ agar tidak terkesan vulgar sangat tepat apabila diungkapkan dengan menggunakan gaya bahasa metafora.

Adanya gaya bahasa metafora akan memudahkan seseorang dalam menyebarkan suatu budaya agar mudah diterima oleh masyarakat. Penyebaran budaya dengan gaya bahasa metafora akan menjadikan ajaran itu menarik dan mudah diikuti oleh masyarakatnya. Melalui $S C$ pengembangan bahasa, sastra, dan budaya Jawa telah berhasil dilakukan oleh Pakubuwana V beserta para pujangga. Ajaran seks dalam $S C$ telah diterima menjadi ajaran leluhur Jawa yang patut diperhitungkan dalam rangka memperkaya khazanah keilmuan nusantara. Gaya bahasa metafora sangat inovatif dan mengandung karakteristik tersendiri untuk menginformasikan pengembangan budaya, salah satunya adalah ajaran seks Jawa. Metafora merupakan kendaraan untuk bertindak, berpikir, mengubah pengalaman dan sebagainya. Metafora senantiasa bisa memberikan respon terhadap siapa pun yang memberikan interpretasinya.

Pakubuwana $\mathrm{V}$ mengemas ajaran seksual Jawa yang penuh dengan gaya bahasa metafora selalu mengkaitkan dengan nama-nama dewa, tempat-tempat yang indah, atau benda-benda yang dianggap suci, sakral yang dimiliki oleh para raja atau dewa. Penggunaan metafora dengan mengkaitkan nama-nama dewa sebagai wujud bahwa kegiatan seksual tidak hanya hubungan biologis semata. Ada hubungan yang lebih suci, lebih tinggi dan agung daripada sekedar hubungan biologis semata. Dengan adanya seks, maka dapat dipergunakan sebagai jalan untuk mendekatkan diri kepada Tuhan.

Pemahaman hakikat seks yang benar akan menjadikan seseorang mengerti pada sangkan 'asal usul' dan paran 'tujuan akhir hidup' yang akan dilalui oleh setiap manusia. Pemahaman sangkan paraning dumadi ini akan lebih mudah diajarkan jika mempergunakan gaya bahasa metafora. Penyebutan alat-alat kemaluan baik laki-laki maupun perempuan, aktivitas persetubuhan, maupun dampak aktivitas persetubuhan dengan gaya bahasa metafora yang santun, dan dihubungkan dengan nama-nama dewa, mampu membuat pembaca untuk lebih memahami makna hidup dan kehidupan.

Tanpa adanya metafora yang santun untuk menyebut alat kemaluan baik laki-laki maupun perempuan, aktivitas persetubuhan, maupun dampak aktivitas persetubuhan, maka pengajaran hakikat seks yang sebenarnya sebagai sarana dalam menyampaikan ajaran kebajikan dari agama 
tidak akan tercapai. Pakubuwana V ternyata mampu mengemas ajaran seks Jawa dengan gaya bahasa metafora yang baik dan indah.

Pakubuwana $\mathrm{V}$ pun membuat metafora-metafora yang berhubungan dengan masalah seksualitas atas dasar pengalaman dirinya. Pakubuwana $\mathrm{V}$ memberikan muatan ajaran seks dalam Serat Centhini karena beliau benar-benar memahami hakikat masalah seks. Ajaran seks menurut Pakubuwana V perlu diajarkan secara benar kepada anak cucu. Seks bukan sesuatu yang tabu atau porno. Seks adalah sesuatu yang sakral, suci, agung sebagai awal adanya penciptaan di dunia.

Oleh karena itu untuk menghindari kesan tabu, porno, jorok, maka beliau banyak mengganti tuturan-tuturan yang tabu, terutama yang berhubungan dengan alat-alat seksual dengan metafora-metafora yang agung, suci, atau banyak mengambil nama-nama yang berhubungan dengan sosok dewa di kahyangan. Pengalaman Pakubuwana V yang memahami hakikat seks, maka beliau mengajarkan masalah seksual tidak secara vulgar, bebas. Ajaran seks dibuat dalam bentuk bahasa susastra yang indah dengan menggunakan metafor-metafor untuk menyebutkan istilah alat-alat kemaluan laki-laki maupun perempuan.

Kemampuan memahami hakikat seks, pengalaman hidupnya sebagai seorang raja yang harus memberikan tuntunan atau ajaran kepada semua orang, maupun kepandaian menyampaikan ajaran seks yang dikemas dengan bahasa-bahasa metafora mampu beliau tunjukkan dalam $S C$ yang dikarangnya bersama para pujangga pada waktu itu. Demikian pula Robert Lowell dalam puisi, beliau mengemas pengalaman pribadinya, kesedihan ketika perang dalam bentuk bahasa-bahasa susastra, metafora-metafora yang apik. Hal ini ternyata juga dilakukan oleh Pakubuwana V selaku pengarang SC. Oleh karena itu pembicaraan seks memerlukan gaya bahasa yang berupa metafora-metafora agar lebih santun dan hubungan seksual tampak indah, bukan sesuatu yang mengerikan. Seks dapat dijadikan sarana untuk mendekatkan diri kepada Tuhan

\section{SIMPULAN}

Metafora ternyata merupakan alat komunikasi yang sangat baik untuk menyampaikan perasaan kasih sayang. Rasa cinta kasih kepada sesama, sahabat, orang yang dicintai, maupun kepada Tuhan sangat efektif jika dipergunakan gaya bahasa metafora. Gaya bahasa metafora akan lebih membuka proses interaktif yang kuat bagaimana menjalankan hubungan cinta kasih yang benar, salah satunya dalam hal seksual. $S C$ yang memuat masalah seksual sebenarnya tidak bisa lepas dari hubungan cinta kasih antara dua insan. Hubungan cinta kasih yang suci dan agung ini sangat tepat jika diungkapkan dengan metafora.

Hubungan cinta kasih yang suci lebih menarik jika disampaikan dengan metaforametafora. Hubungan cinta kasih persebadanan antara dua insan akan menjadi tuturan yang sakral jika disampaikan dalam bentuk metafora. Inilah kehebatan daya metafora. Metafora mampu mengubah persepsi masyarakat atau pembaca mengenai suatu hal. Alat-alat kemaluan laki-laki maupun perempuan yang sangat kasar, porno akan lebih santun dan arif jika diungkapkan dengan metafora. Gaya persetubuhan yang dianggap tabu, porno akan lebih santun jika diungkapkan dengan gaya bahasa metafora. Dampak aktivitas seksual akan tampak lebih santun jika diungkapkan dengan bahasa metafora. Hubungan kasih sayang persebadanan menjadi lebih sakral, suci jika diungkapkan dengan gaya-gaya bahasa metafora.

\section{Daftar Pustaka}

Black, Elizabeth. 2008. Pragmatic Stylistics. Edinburgh: Edinburgh University Press. 
Kamajaya. 1986. Serat Centhini (Suluk Tambangraras) Latin.Jilid 1-12. Yogyakarta: Yayasan Centhini.

Kovesces, Zoltan. 2003. Metaphor and Emotion. Cambridge: Cambridge University Press.

Marsono. 2008. "Centhini: Karya Masterpiece Pujangga Jawa”. Makalah Seminar Centhini.

Fakultas Ilmu Budaya UGM Yogyakarta.

Redaksi. Kajawen Pahargyan Surakarta 200 Taun tentang Pakubuwana V. Balai Pustaka. 